\title{
Technical Performance Scores are strongly associated with early mortality, postoperative adverse events, and intensive care unit length of stay-analysis of consecutive discharges for 2 years
}

\author{
Meena Nathan, MD, ${ }^{a}$ John Karamichalis, MD, ${ }^{a}$ Hua Liu, MS, ${ }^{a}$ Kimberley Gauvreau, ScD, ${ }^{b}$ \\ Steven Colan, MD, ${ }^{\mathrm{b}}$ Matthew Saia, BS, ${ }^{\mathrm{a}}$ Frank Pigula, MD, ${ }^{\mathrm{a}}$ Francis Fynn-Thompson, MD, \\ Sitaram Emani, MD, ${ }^{a}$ Christopher Baird, MD, ${ }^{a}$ John E. Mayer, MD, ${ }^{a}$ and Pedro J. del Nido, MD ${ }^{a}$
}

\begin{abstract}
Objectives: Previous work in our institution has indicated that the Technical Performance Score (TPS) is highly associated with early outcomes in select subsets of procedures and age groups. We hypothesized that the TPS could predict early outcomes in a wide range of diagnoses and age groups.
\end{abstract}

\begin{abstract}
Methods: Consecutive patients discharged from January 2011 to March 2013 were prospectively evaluated. The TPS was assigned according to the discharge echocardiographic findings and the need for reinterventions in the anatomic area of interest. Case complexity was determined using Risk Adjustment for Congenital Heart Surgery (RACHS-1) categories. Early mortality and postoperative adverse events were recorded. Relationships between the TPS and outcomes were assessed after adjusting for the baseline patient characteristics.
\end{abstract}

Results: The median age of the 1926 patients was 1.8 years (range, 0 days to 68 years). Bypass was used in 1740 $(90 \%) ; 322(17 \%)$ were neonates, $520(27 \%)$ infants, $873(45 \%)$ children, $211(11 \%)$ adults. TPS was class 1 (optimal) in $956(50 \%)$, class 2 (adequate) in $584(30 \%)$, and class 3 (inadequate) in $226(12 \%)$; 160 patients $(8 \%)$ could not be scored. A total of 51 early deaths $(2.6 \%)$ and 111 adverse events $(5.7 \%)$ occurred. On univariate analysis, age, RACHS-1 category, and TPS were significantly associated with mortality and the occurrence of adverse events. On multivariate modeling, class 3 (inadequate) TPS was strongly associated with mortality (odds ratio, 16.9; 95\% confidence interval, 6.7-42.9; $P<.001$ ), adverse events (odds ratio, 6.9; $95 \%$ confidence interval, 4.1-11.6; $P<.001$ ), and postoperative intensive care unit length of stay (coefficient, 2.3; 95\% confidence interval, 2.0-2.6; $P<.001$ ) after adjusting for other covariates.

Conclusions: The TPS is strongly associated with early outcomes across a wide range of ages and disease complexity and can serve as important tool for self-assessment and quality improvement. (J Thorac Cardiovasc Surg 2014;147:389-96)

\section{Supplemental material is available online.}

Multiple factors appear to influence the outcomes after congenital cardiac surgery, with success dependent on several components. These components include (1) preoperative factors, such as the preoperative physiologic status

\footnotetext{
From the Departments of Cardiac Surgery ${ }^{\mathrm{a}}$ and Cardiology, ${ }^{\mathrm{b}}$ Boston Children's Hospital, Harvard Medical School, Boston, Mass.

Disclosures: Authors have nothing to disclose with regard to commercial support.

Read at the 93rd Annual Meeting of The American Association for Thoracic Surgery, Minneapolis, Minnesota, May 4-8, 2013.

Received for publication May 5, 2013; revisions received June 20, 2013; accepted for publication July 16, 2013; available ahead of print Sept 16, 2013.

Address for reprints: Meena Nathan, MD, Department of Cardiac Surgery, Boston Children's Hospital, Harvard Medical School, 300 Longwood Ave, Bader 273,

Boston, MA 02215 (E-mail: meena.nathan@ cardio.chboston.org). $0022-5223 / \$ 36.00$

Copyright (C) 2014 by The American Association for Thoracic Surgery http://dx.doi.org/10.1016/j.jtcvs.2013.07.044
}

of the patient, complexity of the defect, adequacy of diagnostic evaluation, and appropriateness of the surgical plan $^{1}$; (2) intraoperative factors, such as cardiopulmonary bypass, surgical technique, and hemodynamic management ${ }^{2-4}$; and (3) postoperative course, including intensive care unit (ICU) events. Among these many factors, the technical adequacy of the repair is likely a significant determinant of a successful outcome.

More than 33,000 surgical procedures are performed annually for congenital heart defects in the United States. ${ }^{5}$ Data from the Centers for Disease Control and Prevention ${ }^{6}$ website have shown that the healthcare costs for hospitalizations for congenital heart defects in the United States were about $\$ 1.4$ billion in 2004, with severe congenital heart defects accounting for $37 \%$ (\$511 million) of the hospital costs associated with congenital heart defects.

The Technical Performance Score (TPS) is a novel tool for assessing operative performance. In previous work at our institution, we developed and validated the TPS initially for 5 procedures. $^{7-9}$ The TPS was further validated in a prospective study of neonates and infants. ${ }^{2,10} \mathrm{We}$ have 


\begin{tabular}{|c|c|}
\hline \multicolumn{2}{|c|}{ Abbreviations and Acronyms } \\
\hline AUC & $\begin{array}{l}=\text { area under the receiver operating } \\
\text { characteristics curve }\end{array}$ \\
\hline CI & $=$ confidence interval \\
\hline ICU & $=$ intensive care unit \\
\hline $\mathrm{RACl}$ & $\begin{array}{l}=\text { Risk Adjustment in Congenital Heart } \\
\text { Surgery }\end{array}$ \\
\hline TPS & $=$ Technical Performance Score \\
\hline VSD & $=$ ventricular septal defect \\
\hline
\end{tabular}

subsequently developed TPS modules to assess $>90 \%$ of congenital cardiac procedures. ${ }^{11,12}$ The purpose of the present study was to assess the utility of TPS for a wide range of procedures, from simple to complex, in a prospective fashion.

\section{METHODS}

Consecutive patients who were admitted after congenital heart surgery from January 2011 to March 2013 were included and prospectively followed up from admission to discharge. The institutional review board approved the present study. Only the index surgery per admission was included in the analysis. The TPS was assigned according to the discharge echocardiographic findings and/or the need for surgical or catheter-based reinterventions in the anatomic area of interest. The Risk Adjustment for Congenital Heart Surgery (RACHS-1) category was used to determine the case complexity. Major postoperative adverse events (excluding unplanned reinterventions) and mortality were recorded. The length of time on the ventilator, ICU stay, and postoperative hospital stay were recorded. Additional information on risk factors such as prematurity, presence of chromosomal anomalies, and other noncardiac anomalies, and patient demographics such as age and gender were documented.

\section{Technical Performance Score}

The TPS was assigned according to the echocardiographic findings and clinical status at discharge from the index operation. The procedures were subdivided into components, and each component was scored as class 1 (optimal), class 2 (adequate), or class 3 (inadequate) using specific echocardiographic criteria. The final score for each operation was determined by the subprocedure scores and was considered class 1 (no residual defect, optimal) if all subprocedure scores were optimal, class 2 (minor residual, adequate) if $\geq 1$ subprocedures were adequate, and class 3 (major residual, inadequate) if $\geq 1$ subprocedures were graded as inadequate. Any unplanned reintervention, whether surgical or catheter based, on the anatomic area initially treated at the index surgery or the need for permanent pacemaker placement resulted in a class 3 (inadequate) score. ${ }^{1,2,7-12}$ Only operations or catheter reinterventions performed on the anatomic area treated at the index operation (eg, closure of a residual ventricular septal defect [VSD], repeat repair of a semilunar or an atrioventricular valve, conversion of an infundibular patch to a transannular patch in valve-sparing tetralogy repair, branch pulmonary artery stenting after pulmonary artery-plasty) were considered class 3 (inadequate). Planned reinterventions such as delayed chest closure and planned pulmonary artery rehabilitation were not considered TPS class 3 . For the purpose of the present study, to avoid bias and allow inclusion of all patients, we included a fourth category labeled "not assigned," for those patients for whom a TPS could not be assigned because no echocardiogram had been performed, because the postoperative studies were incomplete, or the involved procedures, such as vascular rings, pacemakers, ventricular assist device, and others for which a score has not been developed.

\section{RACHS-1 Mortality Category}

The RACHS-1 method was developed to adjust for baseline case mix differences in risk when comparing in-hospital mortality among groups of patients aged $<18$ years undergoing congenital heart surgery. Procedure and diagnosis codes were used to place the surgical procedures into 6 predefined categories with similar risks of in-hospital mortality. Category 1 had the lowest risk of death and category 6 , the highest. Patients with combinations of cardiac surgical procedures (eg, repair of coarctation of the aorta and VSD closure) were placed in the risk category corresponding to the single greatest risk procedure. ${ }^{13,14}$ For the purposes of the present study, to include the entire cohort, even those for whom the RACHS-1 method has not been validated, we created 2 additional categories-category 7 and category 8 . Category 7 included all patients aged $<18$ years who could not be assigned a RACHS- 1 score. This group of patients included patients who were aged $<18$ years, who were undergoing other complex procedures that could not be assigned a RACHS-1 category, such as biventricular recruitment, ventricular assist devices, transplants (eg, heart and lung). Category 8 included all adults.

\section{Outcomes of Interest}

The outcomes included in the present analysis were early mortality, adverse events, and postoperative ICU length of stay. Early mortality was defined as death in the hospital or death within 30 days of the index operation if discharged before 30 days. Adverse events included those events included in the Society of Thoracic Surgeons criteria, ${ }^{15,16}$ such as (1) the need for extracorporeal membrane oxygenator support; (2) re-exploration for bleeding; (3) cardiac arrest requiring resuscitation; (4) re-exploration for hemodynamic instability; (5) diaphragm plication for paralysis or paresis of the diaphragm; (6) stroke; (7) mediastinitis requiring exploration and debridement; and (8) renal failure requiring dialysis. Unplanned surgical or catheter-based reinterventions in the treated anatomic area and placement of permanent pacemakers were not included as adverse events, because they are components of the TPS.

\section{Statistical Analysis}

Categorical variables are summarized as numbers and percentages and continuous variables as medians and ranges. The rates of in-hospital mortality and complications were compared across TPS classes using the chi-square test, and the postoperative ICU length of stay was compared using the Kruskal-Wallis test. Similarly, mortality and complication rates were compared by the baseline patient characteristics using the chi-square test. The Mann-Whitney $U$ and Kruskal-Wallis tests were used for the postoperative ICU length of stay. To adjust for baseline patient characteristics, multivariate logistic and linear regression analysis was used. For TPS, class 1 (optimal) technical performance was used as the reference group. For the RACHS-1 categories, categories 1 and 2 were combined to serve as the reference group (because no deaths or adverse events occurred in RACHS-1 category 1). In the logistic regression models, discrimination of the factors for predicting mortality and major postoperative adverse events was assessed using the area under the receiver operating characteristic curve. For the linear regression model, the coefficient of determination is presented. A log transformation was applied to the outcome, postoperative ICU length of stay, because of the skewed distribution of this variable. IBM SPSS Statistics, version 18, for Windows (SPSS Inc, Chicago, Ill) was used for statistical analysis.

\section{RESULTS}

A total of 1926 operations were done in 1714 unique patients. The baseline patient characteristics for the 1926 
TABLE 1. Patient characteristics

\begin{tabular}{|c|c|}
\hline Characteristic & Value \\
\hline Male gender & $1059(55)$ \\
\hline \multicolumn{2}{|l|}{ Age at surgery } \\
\hline$\leq 30 \mathrm{~d}$ & $322(16.7)$ \\
\hline$\overline{3} 1 \mathrm{~d}$ to $1 \mathrm{y}$ & $520(26.9)$ \\
\hline $1 \mathrm{y}$ to $<18 \mathrm{y}$ & $873(45.3)$ \\
\hline$\geq 18$ y & $211(10.9)$ \\
\hline Weight $(\mathrm{kg})$ & $11(1-147)$ \\
\hline Prematurity (<37 wk) & $67(3.4)$ \\
\hline Extracardiac and chromosomal anomaly & $369(19.1)$ \\
\hline \multicolumn{2}{|l|}{ RACHS-1 risk category } \\
\hline 1 & $179(9.2)$ \\
\hline 2 & $526(27.3)$ \\
\hline 3 & $594(30.8)$ \\
\hline 4 & $186(9.6)$ \\
\hline 6 & $62(3.2)$ \\
\hline 7 (Could not assign, $<18$ y) & $168(8.7)$ \\
\hline 8 (Adults) & $211(10.9)$ \\
\hline \multicolumn{2}{|l|}{ STS/EACTS category } \\
\hline 1 & $726(37.6)$ \\
\hline 2 & $569(29.5)$ \\
\hline 3 & $138(7.1)$ \\
\hline 4 & $346(17.9)$ \\
\hline 5 & $98(5.0)$ \\
\hline Could not assign & $49(2.5)$ \\
\hline \multicolumn{2}{|l|}{ TPSs } \\
\hline Class 1, optimal, no residual & $956(49.6)$ \\
\hline Class 2 , adequate, minor residual & $584(30.3)$ \\
\hline $\begin{array}{l}\text { Class } 3 \text {, inadequate, major residual, or predischarge } \\
\text { reintervention }\end{array}$ & $226(11.7)$ \\
\hline NA, TPS score not assigned & $160(8.3)$ \\
\hline Early or in-hospital mortality & $51(2.6)$ \\
\hline Adverse Events (excluding unplanned reinterventions) & $111(5.8)$ \\
\hline Ventilator use $(\mathrm{d})$ & $1(0-424)$ \\
\hline ICU stay $(d)$ & $2(0-424)$ \\
\hline Hospital (d) & $7(1-424)$ \\
\hline
\end{tabular}

Data presented as $\mathrm{n}(\%)$ for categorical variables and median (range) for continuous variables. RACHS-1, Risk Adjustment in Congenital Heart Surgery; STS/EACTS, Society of Thoracic Surgeons/European Association for Cardio-Thoracic Surgery; TPS, Technical Performance Score; $N A$, not assigned; $I C U$, intensive care unit.

admissions are presented in Table 1 . A total of 51 deaths $(2.6 \%)$ and 111 adverse events $(5.8 \%)$ occurred, and the median ICU length of stay for the entire cohort was 2 days (range, 0-424). An unadjusted comparison of the outcomes based on the TPS is presented in Table E1 and Figure E1. The relationship between the TPS and RACHS-1 for mortality and adverse events is presented in Figure E2.

\section{Mortality}

On univariate analysis, TPS, age, RACHS-1 category, prematurity, and the presence of chromosomal or other noncardiac anomalies were all significantly associated with mortality $(P \leq .001$; Table E2). On multivariate modeling, after adjusting for variables that were significant on univariate analysis, the TPS remained strongly associated with mortality. A class 3 (inadequate) TPS had an odds ratio of 16.9 (95\% confidence interval $[\mathrm{CI}], 6.8-42.9 ; P<.001)$ for mortality compared with a class 1 (optimal) TPS (Table 2).

\section{Adverse Events and Complications}

Similarly, on univariate analysis TPS, age, RACHS-1 category, and prematurity were all significantly associated with these outcomes $(P<.001)$. However, the presence of chromosomal or other noncardiac anomalies was not a significant factor $(P=.354$; Table E3). On multivariate modeling, after adjusting for other significant variables, TPS remained strongly associated with adverse events. A class 3 (inadequate) TPS had an odds ratio of $6.9(95 \%$ CI, 4.1-11.7; $P<.001$ ) compared with class 1 (optimal) TPS for adverse events (Table 3 ).

\section{Postoperative ICU Length of Stay}

On univariate analysis, TPS, age, RACHS-1 category, prematurity, and the presence of chromosomal or other noncardiac anomalies were all significantly associated with the postoperative ICU length of stay $(P<.001$; Table E4, Figure E3). On multivariate modeling, after adjusting for these significant variables, the TPS remained strongly associated with the postoperative ICU length of stay $(P<.001)$. A class 3 (inadequate) TPS had a coefficient of 2.3 (95\% CI, 2.0- 2.6; Table 4).

We performed a subgroup analysis of the patients with TPS class 3 (inadequate). In the entire cohort of 1926 patients, $226(12 \%)$ had class 3 (inadequate) TPS.

TABLE 2. Multivariate modeling for mortality $(n=51 / 1926)$

\begin{tabular}{lrcc}
\hline \multicolumn{1}{c}{ Variable } & OR & $\mathbf{9 5} \% \mathbf{C I}$ & $\boldsymbol{P}$ value \\
\hline RACHS-1 risk category & & & \\
$1-2$ & 1.0 & - & - \\
3 & 2.3 & $0.6-8.9$ & .222 \\
4 & 4.8 & $1.2-20.4$ & $.031^{*}$ \\
6 & 3.8 & $0.7-20.9$ & .126 \\
7 (NA, <18 y) & 8.1 & $2.0-32.4$ & $.003^{*}$ \\
8 (Adults) & 11.0 & $1.8-68.8 \dagger$ & $.010^{*}$ \\
Age at surgery & & & \\
S30 d & 5.9 & $2.1-16.9$ & $.001^{*}$ \\
31 d to 1 y & 3.8 & $1.4-10.5$ & $.009^{*}$ \\
1-18 y & 1.0 & - & - \\
Prematurity & 5.8 & $2.4-13.9$ & $<.001^{*}$ \\
Extracardiac and genetic anomalies & 3.1 & $1.5-6.2$ & $.002^{*}$ \\
TPS & & & \\
Class 1, optimal & 1.0 & - & - \\
Class 2, adequate & 0.7 & $0.2-2.7$ & .576 \\
Class 3, inadequate & 16.9 & $6.7-42.9$ & $<.001^{*}$ \\
$\quad$ NA, TPS not assigned & 2.6 & $0.7-9.7$ & .151 \\
\hline
\end{tabular}

$O R$, Odds ratio; $C I$, confidence interval; RACHS-1, Risk Adjustment in Congenital Heart Surgery; NA, not assigned; TPS, Technical Performance Score. *Statistically significant. †Only 3 deaths occurred in adults, explaining the large 95\% CI. 
TABLE 3. Multivariate modeling for adverse events $(n=111 / 1926)$

\begin{tabular}{lccc}
\hline \multicolumn{1}{c}{ Variable } & OR & $\mathbf{9 5} \%$ CI & $\boldsymbol{P}$ value \\
\hline RACHS-1 risk category & & & \\
$1-2$ & 1.0 & - & - \\
3 & 2.5 & $1.2-5.5$ & $.018^{*}$ \\
4 & 6.6 & $2.9-15.0$ & $<.001^{*}$ \\
6 & 7.7 & $2.8-21.2$ & $<.001^{*}$ \\
7 (NA, $<18$ y) & 7.4 & $3.2-17.5$ & $<.001$ \\
8 (Adults) & 2.6 & $0.7-9.0$ & .139 \\
Age at surgery & & & \\
$\quad \leq 30$ d & 3.0 & $1.6-5.7$ & $.001^{*}$ \\
31 d to 1 y & 2.7 & $1.5-4.8$ & $.001^{*}$ \\
1-18 y & 1.0 & - & - \\
Prematurity & 2.9 & $1.4-6.0$ & $.004^{*}$ \\
Extracardiac and genetic anomalies & 1.2 & $0.7-2.0$ & .516 \\
TPS & & & \\
$\quad$ Class 1, optimal & 1.0 & - & - \\
Class 2, adequate & 0.7 & $0.4-1.4$ & .346 \\
Class 3, inadequate & 6.9 & $4.1-11.7$ & $<.001^{*}$ \\
$\quad$ NA, TPS not assigned & 1.0 & $0.4-2.5$ & .977 \\
\hline
\end{tabular}

$O R$, Odds ratio; $C I$, confidence interval; $R A C H S$-1, Risk Adjustment in Congenital Heart Surgery; NA, not assigned; TPS, Technical Performance Score. *Statistically significant.

Among the 139 patients undergoing surgical or catheterization reintervention, $21(15 \%)$ were assigned TPS class 3 because of the need for a permanent pacemaker. The distribution of TPS echocardiographic scores in the pacemaker patients was $29 \%$ class 1 (optimal), $57 \%$ class 2 (adequate), and $14 \%$ class 3 (inadequate). Of the other 118 patients $(85 \%$ of reinterventions) who had undergone an unplanned surgical or catheter-based reintervention (excluding pacemakers) and were therefore placed in class 3

TABLE 4. Multivariate modeling for postoperative ICU length of stay as surrogate for resource usage $(n=1926)$

\begin{tabular}{lccc}
\hline \multicolumn{1}{c}{ Variable } & Coefficient & $\mathbf{9 5} \% \mathbf{C I}$ & $\boldsymbol{P}$ value \\
\hline RACHS-1 risk category & & & \\
$1-2$ & - & - & - \\
3 & 1.7 & $1.6-1.9$ & $<.001$ \\
4 & 2.3 & $2.0-2.7$ & $<.001$ \\
6 & 2.8 & $2.2-3.5$ & $<.001$ \\
7 (NA and age $<18$ y) & 2.3 & $2.0-2.7$ & $<.001$ \\
8 (Adults) & 1.4 & $1.2-1.6$ & $<.001$ \\
Age at surgery & & & \\
$\leq 30$ d & 2.6 & $2.3-3.0$ & $<.001$ \\
30 d to 1 y & 1.6 & $1.5-1.8$ & \\
Prematurity & 1.8 & $1.4-2.2$ & $<.001$ \\
Extracardiac defect & 1.2 & $1.1-1.3$ & $<.001$ \\
TPS & & & \\
Class 1, optimal & - & - & - \\
Class 2, adequate & 1.2 & $1.1-1.3$ & $<.001$ \\
Class 3, inadequate & 2.3 & $2.0-2.6$ & $<.001$ \\
NA, TPS not assigned & 0.8 & $0.7-1.0$ & .024 \\
\hline All $P$ vas we
\end{tabular}

All $P$ values were statistically significant. $\mathrm{R}^{2}=40 \%$. CI, Confidence interval; RACHS-1, Risk Adjustment in Congenital Heart Surgery; NA, not assigned; TPS, Technical Performance Score; ICU, intensive care unit. (inadequate), $101(86 \%)$ had preintervention echocardiograms that could be coded, and all belonged to class 3 (inadequate). The remaining 17 patients $(14 \%)$ either had echocardiograms that could not be classified or had no echocardiogram but had undergone an unplanned reintervention because of clinical indications.

All analyses were repeated using only the 1714 unique patients, and the findings were similar, with TPS an independent predictor for mortality, complications, and postoperative ICU length of stay after adjusting for other important predictive variables.

The robustness of the models in predicting outcomes is presented in Figure 1. The model for mortality had an area under the receiver operating characteristics curve (AUC) of 0.92 (95\% CI, 0.88-0.96), and the model for adverse events had an AUC of 0.86 (95\% CI, 0.82-0.89). The addition of TPS increased the AUC from 0.87 to 0.92 for mortality and from 0.81 to 0.86 for adverse events.

\section{DISCUSSION}

In previous work, we have demonstrated that class 1 (optimal) technical performance was associated with lower adverse event rates and a lower postoperative ICU length of stay $^{2}$ and that class 1 (optimal) TPS was able mitigate the effects of the preoperative severity of illness in a specific subset of high-risk procedures (ie, stage I Norwood procedure). ${ }^{1,9}$ An association was also found between TPS and midterm outcomes. ${ }^{10,17}$

The present study has demonstrated the ability of TPS to predict early outcomes such as mortality, adverse events, and increased resource use in a diverse set of patients in a single institution. We included all consecutive patients in the present study, and the greater power allowed for better risk adjustment. We were also able to include other important preoperative variables such as prematurity, age, and presence of genetic and other noncardiac anomalies in our model, which have previously been shown to play important roles in the outcomes after congenital cardiac surgery. ${ }^{18-20}$ We chose not to include intraoperative variables and postoperative variables in our analysis because of the high co-linearity between the TPS and these variables.

Although mortality has been routinely used as an important benchmark of a center's performance, advances in surgical technique in the past 2 decades have significantly improved survival. Therefore, mortality has become less useful in comparisons between hospitals for performance evaluation. ${ }^{18}$ The TPS might thus serve as an important bench mark for evaluation of each center's performance.

Congenital cardiac surgery admissions (admissions included both medical and surgical) have a reported complication rate as great as $32 \% .{ }^{19,20}$ Furthermore, these studies showed a greater risk of mortality in patients with complications after adjusting for other important 


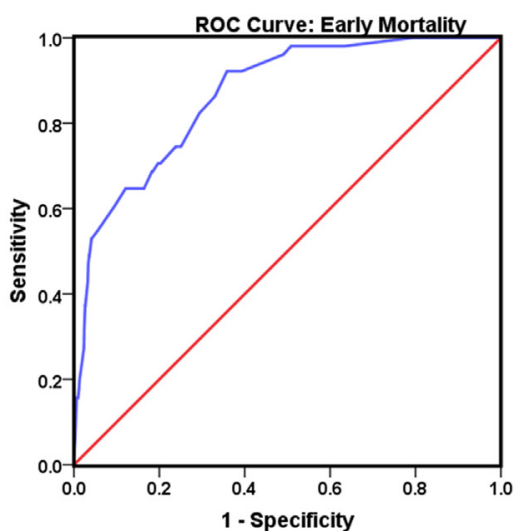

Model includes RACHS-1 category, Age Prematurity and Non Cardiac Anomalies AUC 0.866 (Cl 0.821- 0.911)

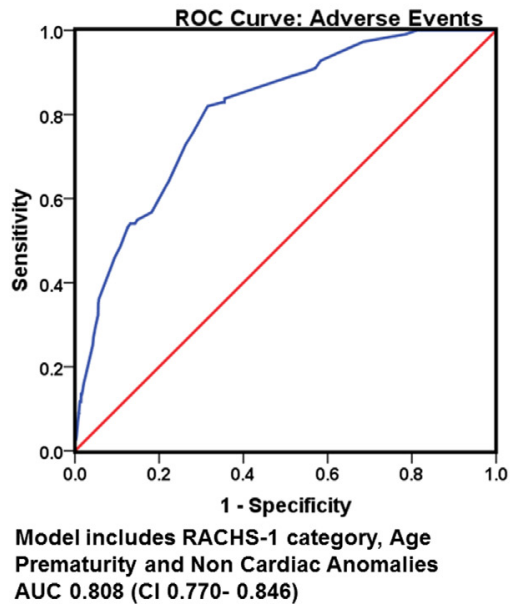

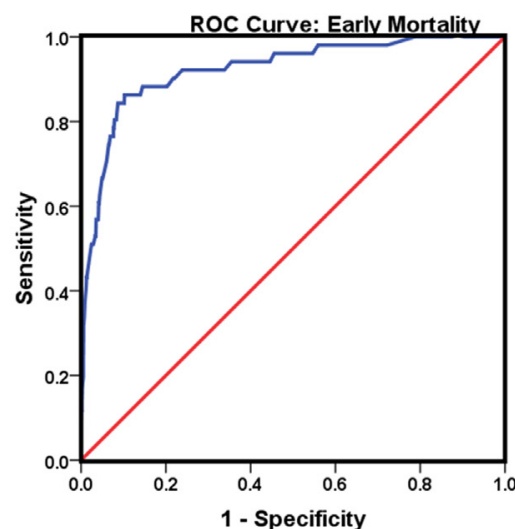

Model includes RACHS-1 category, Age Prematurity, Non Cardiac Anomalies and TPS AUC $0.923(\mathrm{Cl} 0.883-0.964)$

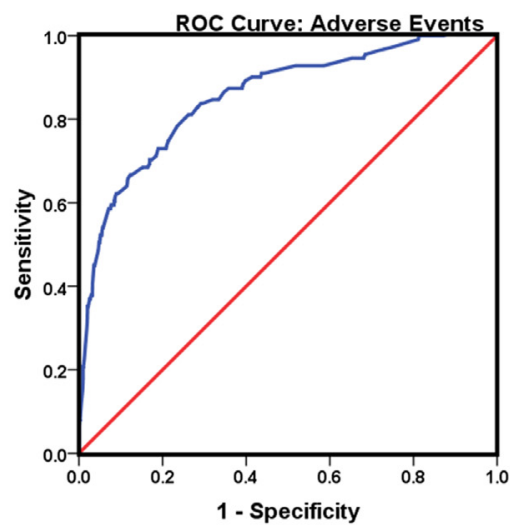

Model includes RACHS-1 category, Age Prematurity, Non Cardiac Anomalies and TPS AUC 0.855 (Cl 0.817- 0.893)

FIGURE 1. Area under the receiver operator characteristics $(R O C)$ curve $(A U C)$ for mortality and adverse events. Top, ROC curves for mortality, with (left), the entire model and (right), curve for Technical Performance Score. Bottom, ROC curves for adverse events, with (left), the entire model and (right), the ROC curve for Technical Performance Score. RACHS-1, Risk adjustment in congenital heart surgery; CI, confidence interval.

predictive variables. Our study had a complication rate of $5.8 \%$ related to the use of the more stringent Society of Thoracic Surgeons criteria for adverse events, with additional exclusion of unplanned surgical and catheter reinterventions and unplanned permanent pacemaker placement. Despite these lower rates, the TPS had a strong association with the occurrence of adverse events, with an odds ratio of 6.8 and the TPS having an AUC of 0.69 (Figure 1). Early recognition of an inadequate repair and intervention, perhaps even in the operating room, might help reduce the complication rate and associated mortality. ${ }^{2}$

Congenital heart disease has been well documented to be associated with high resource usage. ${ }^{6}$ Furthermore, mortality and complications after congenital heart surgery are known to be associated with greater resource use. ${ }^{21}$ Although healthcare costs remain an important measure of resource use, the psychosocial effect of prolonged hospitalization and/or multiple complications and mortality might well be more important ${ }^{20,22}$ in the long term for both patients and family. The TPS, with its ability to predict midterm outcomes such as postdischarge mortality and unplanned reinterventions, ${ }^{10,17}$ might thus serve as a tool that recognizes a subgroup of patients who need closer monitoring.

Our subgroup analysis of patients with TPS class 3 (inadequate) showed that a little less than two thirds $(62 \%)$ were assigned a TPS class 3 (inadequate) only because of the need for unplanned reinterventions and not from echocardiographic class 3 (inadequate) results. Among those for whom the unplanned reintervention was in the treated anatomic area at the index operation, $86 \%$ had had echocardiograms before the reintervention that were scored as class 3 (inadequate), clearly indicating a strong association between technical adequacy and the need for reintervention.

It was also interesting to note that among the RACHS-1 categories, as expected, the RACHS- 1 category 6 had greater mortality and adverse events and a longer postoperative ICU length of stay. Although this was expected, we also noted that those in RACHS-1 category 7 
(those who were $<18$ years and for whom the RACHS-1 category could not be assigned) also had greater mortality and adverse events and a longer postoperative ICU length of stay. This could have been because this group predominantly consisted of patients who have undergone more complex procedures, such as biventricular recruitment in hypoplastic left heart, biventricular conversion after single ventricle palliation, VADS for end-stage heart failure, and certain complex heart and lung transplants.

\section{Study Limitations}

The present study represents a single center's experience with validation of the TPS. Testing the reproducibility of this tool across multiple centers is necessary. Furthermore, validation of the association of TPS with long-term outcomes is required. We are in the process of collecting long-term prospective data for this cohort. Although the present study included larger numbers of patients in each of the RACHS-1 categories, ideally, the association between TPS and early outcomes should be studied in individual procedural groups. We are currently involved in a multicenter study to validate the TPS prospectively in specific procedural groups, and we anticipate that this will allow us to weight each component of the score and determine the predictive value of each component. This information will be particularly important, because it would allow the TPS to be used as a tool that can help determine which patient would warrant early intervention to avoid morbidity.

\section{CONCLUSIONS}

The TPS has been shown to have a strong association with early outcomes such as mortality, adverse events, and increased resource use. It might thus allow the development of predictors for early intervention for residual anatomic problems. We speculate that it could lead to an improvement in the long-term physical, neurologic, and psychosocial development in this vulnerable high-risk population by identifying patients who would benefit from early intervention and decrease the burden of prolonged illness on patients with congenital heart disease and their families.

We would like to acknowledge Emile Bacha, MD, and Kathy Jenkins, MD, for their contributions to the development of the technical performance score.

\section{References}

1. Karamichalis JM, Thiagarajan RR, Liu H, Mamic P, Gauvreau K, Bacha EA Stage I Norwood: optimal technical performance improves outcomes irrespective of pre-operative physiologic status or case-complexity. J Thorac Cardiovasc Surg. 2010;139:962-8.

2. Nathan M, Karamichalis J, Liu H, del Nido P, Pigula F, Thiagarajan R, et al. Intraoperative adverse events can be compensated in infants after cardiac surgery: a prospective study. J Thorac Cardiovasc Surg. 2011;142:1098-107.

3. de Leval MR, Carthey J, Wright DJ, Farewell VT, Reason JT. Human factors and cardiac surgery: a multicenter study. J Thorac Cardiovasc Surg. 2000;119:661-72.
4. Barach P, Johnson JK, Ahmad A, Galvan C, Bognar A, Duncan R, et al. A prospective observational study of human factors, adverse events and patient outcomes in surgery for pediatric cardiac disease. J Thorac Cardiovasc Surg. 2008;136:1422-8.

5. Duke Clinical Research Institute. Data analysis of the Society of Thoracic Surgeons congenital heart surgery database, period ending 6/30/2011. Available at: https:// outcomes.dcri.duke.edu/registry. Accessed January 28, 2013.

6. Centers for Disease Control and Prevention. Congenital heart defects. Data and statistics. Available at: http://www.cdc.gov/ncbddd/heartdefects/data.html. Accessed January 28, 2013.

7. Larrazabal LA, del Nido PJ, Jenkins KJ, Gauvreau K, Lacro S, Colan SD, et al. Measurement of technical performance in congenital heart surgery: a pilot study. Ann Thorac Surg. 2007;83:179-84.

8. Bacha EA, Larrazabal LA, Pigula FA, Gauvreau K, Jenkins KJ, Colan SD, et al. Measurement of technical performance in surgery for congenital heart disease: the stage I Norwood procedure. J Thorac Cardiovasc Surg. 2008;136:993-7.

9. Shuhaiber J, Gauvreau K, Thiagarjan R, Bacha EA, Mayer JE, del Nido PJ, et al. Congenital heart surgeon's technical proficiency affects neonatal hospital survival. J Thorac Cardiovasc Surg. 2012;144:1119-24.

10. Nathan M, Karamichalis JM, Colan S, Liu H, Pigula FA, Fynn-Thompson F, et al. Surgical technical performance scores are predictors for late mortality and unplanned reinterventions in infants after cardiac surgery. J Thorac Cardiovasc Surg. 2012;144:1095-101.

11. Karamichalis JM, Colan SD, Nathan M, Pigula FA, Baird CB, Marx G, et al. Technical performance scores in congenital cardiac surgery: a quality assessment initiative. Ann Thorac Surg. 2012;94:1317-23.

12. Karamichalis JM, Barach P, Nathan M, Henaine R, del Nido PJ, Bacha EA. Assessment of technical competency in pediatric cardiac surgery. Prog Pediatr Cardiol. 2012;33:15-20.

13. Jenkins KJ, Gauvreau K, Newburger JW, Spray TL, Moller JH, Iezzoni LI. Consensus based method for risk adjustment for surgery for congenital heart disease. J Thorac Cardiovasc Surg. 2002;123:110-8.

14. Jenkin KJ. Risk adjustment for congenital heart surgery: the RACHS-1 method. Semin Thorac Cardiovasc Surg. 2004;7:180-4.

15. Jacobs JP, Jacobs ML, Mavroudis C, Maruszewski B, Tchervenkov CI, Lacour-Gayet FG, et al. What is operative morbidity? Defining complications in a surgical registry database: a report from the STS Congenital Database Taskforce and the Joint EACTS-STS Congenital Database Committee. Ann Thorac Surg. 2007;84:1416-21.

16. Jacobs JP, Benavidez OJ, Bacha EA, Walters HL III, Jacob ML. The nomenclature of safety and quality of care for patients with congenital cardiac disease: a report of the Society of Thoracic Surgeons Congenital Database Taskforce Subcommittee on Patient Safety. Cardiol Young. 2008;18(Suppl 2):81-91.

17. Nathan M, Pigula FA, Liu H, Gauvreau K, Colan SD, Fynn-Thompson F, et al. Inadequate technical performance scores are associated with late mortality and late reinterventions. Ann Thorac Surg. 2013;96:664-9.

18. Welke KF, Karamlou T, Ungerleider RM, Diggs BS. Mortality is not a valid indicator of quality differences between pediatric cardiac surgical programs. Ann Thorac Surg. 2012;89:139-46.

19. Benavidez OJ, Gauvreau K, Jenkins KJ. Medical injuries and congenital heart surgery. Pediatr Res. 2005;58:359.

20. Benavidez OJ, Gauvreau K, del Nido P, Bacha Jenkins KJ. Complications and risk factors for mortality during congenital heart surgery admissions. Ann Thorac Surg. 2007;84:147-55.

21. Benavidez OJ, Connor JA, Gauvreau K, Jenkins KJ. The contribution of complications to high resource utilization during congenital heart surgery admissions. Congenit Heart Dis. 2007;2:319-26.

22. Connor JA, Kline NE, Mott S, Harris SK, Jenkins KJ. The meaning of cost for families of children with congenital heart disease. J Pediatr Health Care. 2010;24:318-25.

\section{Discussion}

Dr Christopher A. Caldarone (Toronto, Ontario, Canada). My only disclosure is that I am a fan of technical performance scores.

"Mirror, mirror on the wall, who's the fairest of them all," so said the witch. She wanted to know how she stacked up against her peers. How did her blemishes compare to the blemishes of others? As surgeons, we all want to know the same. Aside from 
comparing gross measures of mortality, we have very little ability to compare the residual lesions we commonly leave behind.

Dr Nathan and her team should be congratulated for extending the pioneering work of Emile Bacha in developing the concept of technical performance scores, a systematic approach to identifying the significance of residual lesions. You have shown us that residual lesions are common, and they contribute to mortality. This is a deceptively simple, yet transformative, concept, a mirror that we all need.

I have a few questions that will focus on a critique of the method.

First, your team evaluates numerous components for the surgical procedure and grades each component into 3 categories. This approach provides simplicity but results in inevitable loss of important information. Supporting this notion is your finding that there is very little difference between the adequate and optimal score categories-suggesting a loss of information by categorization. Why did you not create a scoring system in which continuous variables are maintained and derive a score that is itself a continuous variable? This would avoid potentially sensitive terms such as "inadequate" and provide greater discrimination of outcomes.

Second, your methodology includes the laudable concept of downgrading a technical performance score to match the lowest component score. This is based on the premise that each component has equal clinical significance. However, the clinical significance of 1 residual lesion could be different from another. How will you refine your scoring system in the future to take into account the difference in clinical significance of these various components?

Third, in the current version of your scoring system, when a region is not addressed by the surgeon, it is not included in the TPS. Thus, a patient with residual tricuspid insufficiency, for example, is included in the scoring system if the surgeon addressed the tricuspid valve but is not included in the scoring system if the surgeon chose not to address the residual lesion. Although this approach keeps the scoring system focused on the interventions of the surgeon, it ignores the effect of untouched residual lesions, which are of importance to the patient. Dr Nathan, should an assessment of surgical performance be limited to the subroutines performed by the surgeon or should performance be determined by the patient's overall freedom from residual lesions?

Finally, as you know, the Congenital Heart Surgeons Society, in collaboration with members of your team, has developed a webbased data entry system to provide a technical performance "mirror" for our participants. This system will provide new information for us to improve our patient care, but it is not clear how we will transform the concept of a TPS into improved outcomes. How do you distribute, discuss, and use TPS in Boston to improve patient outcomes? I want to thank the Association for the privilege to discuss this study.

Dr Nathan. Thank you, Dr Caldarone. Let me answer your first question, which was why we use a categorical system of scoring. The reason we chose a categorical system of scoring is because it is easily reproducible and can be used across centers. Although this does lead to some loss of information, this will allow us to test and validate the score across multiple institutions. We are actually in the process of accruing patients for a prospective multi-institutional trial. However, it is important that we also consider other methods of assessing this score.

Your second question was why all components are scored equally, and I agree with you that this is something that needs clarification. For example, a residual VSD in tetrology of Fallot is an entirely different beast than a residual VSD in primary VSD repairs. If you had a large residual VSD in tetrology of Fallot, the patients tend to do worse. Now that we have gathered data for about 2 to 3 years, we are studying the subcomponents for each procedure, and we are going to determine which of these subcomponents is important for each procedure. Hopefully, we will have the analysis in a year or 2 .

Your third question was related to why we did not score residual lesions that are not intervened on. When we initially started the score, the plan was to assess the intent to treat, but only the components that the surgeon operated on were assessed. But I do agree with you, for example, in a VSD, if after a repair, you were left with greater than mild tricuspid regurgitation, I think the score would be inadequate, and we are in the process of refining the score to reflect this.

Your final question had been about how we used the score to assess how well we did. We have weekly conferences, and we review each of the surgeon's scores and determine how a procedure that had an inadequate score could have been performed better. We also have monthly mortality and morbidity conferences. Currently, we now assign scores for the intraoperative echocardiograms, and we will compare these with the discharge echocardiograms. Perhaps that will help us determine when the intervention needs to be done; thus, this tool could serve not only as an assessment tool, but also as an interventional tool.

I hope I answered all your questions.

Dr Caldarone. You did.

Dr Francois G. Lacour-Gayet (New York, NY). Dr Nathan, I enjoyed very much your presentation, and we have followed this TPS that was initiated by Dr Bacha with great interest. I have a question of method. How can you predict early death using a discharge echocardiogram?

Dr Nathan. I know that is an important question. Currently, the tool is just a retrospective assessment of outcomes based on the discharge echocardiogram. This is one of the reasons we are taking more interest in the intraoperative score, because I think the intraoperative score will be able to help us determine what needs to be done to prevent mortality.

Glenn Van Arsdell (Toronto, Ontario, Canada). That was a beautiful study, and I fully agree with it but have a little caveat. One year ago, we presented a similar controversial report that suggested if you chase after all these residual lesions in the operating room, you shift error to the ICU and that the intensive care performance also affects the outcome. I think back to a book from your institution in 1994 in which Aldo Castaneda said, nowhere in the practice of medicine is it more important to have a harmonious action between many different segments of medicine, intensive care, anesthesia, perfusion, nursing, and so forth.

Why do you suppose in your study we do not see that importance? It appears in your study that it really is only surgical performance that matters, not diagnostic performance, not intensive care performance. In our study, we saw each of those components being very important. 
Dr Nathan. Thank you. I do agree that care in the ICU plays a role in the ultimate outcome; however, if a procedure is done well, I think it can mitigate some of these effects. In a previous study, we had shown that in the stage I population, if they had an optimal score, it was able to mitigate the effects of preoperative status, as determined by Pediatric Risk of Mortality scores and also postoperative status determined by Pediatric Risk of Mortality and other ICU variables.

Also, although all components shown in this chart are important for outcomes, I think the TPS perhaps has a more important role to play. If you can achieve a good operation, I think you minimize a number of the problems seen in the postoperative period.

Dr Carl L. Backer (Chicago, Ill). I congratulate you on using this TPS to try and improve the quality of our outcomes.
The question I have is, do you have information about what the surgeon did with the intraoperative transesophageal echocardiographic results? Your performance score mostly relies on echocardiographic residual lesions. We use intraoperative transesophageal echocardiogram to identify residual lesions, and then, in a certain percentage of our patients, we correct those residual lesions immediately in the operating room. What percentage of patients underwent attempts to address those residual lesions in the operating room at the original procedure according to an intraoperative transesophageal echocardiogram?

Dr Nathan. We are studying that data now; however, approximately $3 \%$ to $4 \%$ had a return to bypass to fix a residual lesion, and this is mostly related to valve repairs. That is why it is important that we consider those intraoperative scores and discharge scores and see what the difference is in outcomes. 
Mortality/TPS

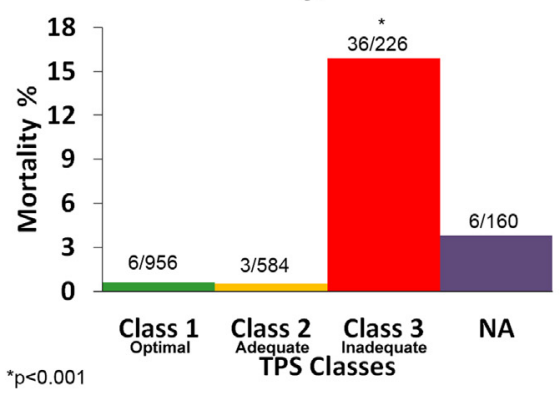

Adverse Events/TPS

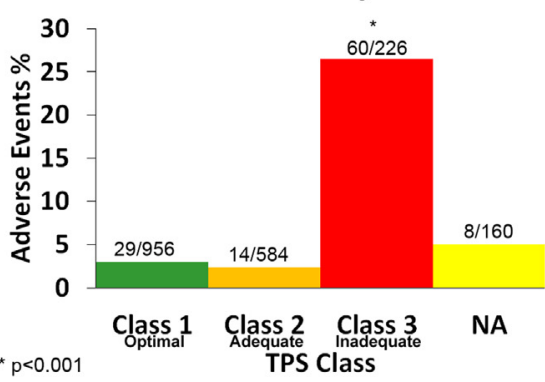

FIGURE E1. Mortality and adverse events according to Technical Performance Score (TPS). The number of events and total number of patients in each group is presented above each bar. NA, Technical performance score could not be assigned.
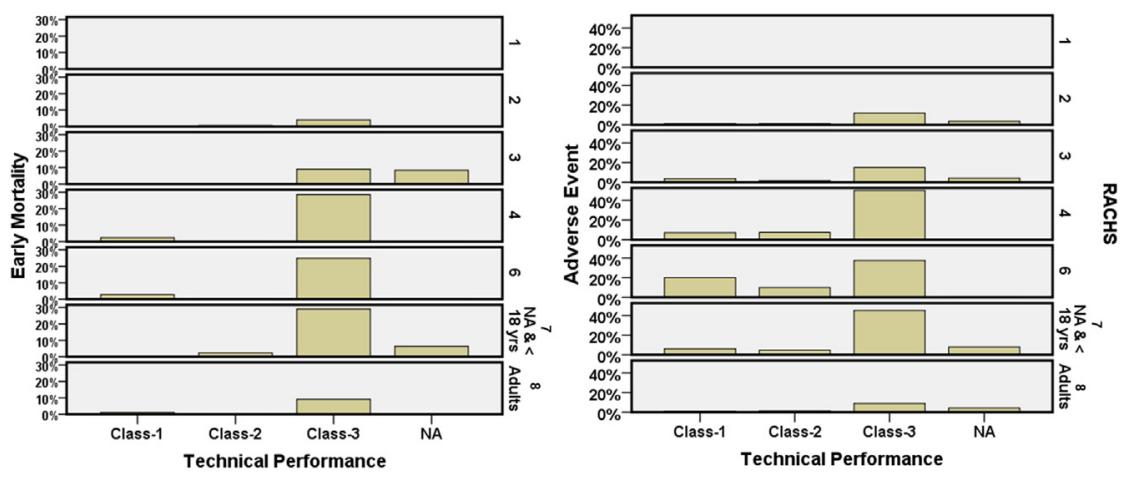

FIGURE E2. Postoperative intensive care unit (ICU) length of stay according to Technical Performance Score (TPS). The postoperative intensive care unit length of stay for each TPS class is represented as a box plot. The outliers are represented by asterisks and open circles. The median is represented by the line in the center of each box, and the whiskers represent the 25 th and 75 th percentile. Class 3 (inadequate) TPS had a significantly greater median length of stay (LOS). NA, No TPS score could be assigned; RACHS, Risk Adjustment in Congenital Heart Surgery.

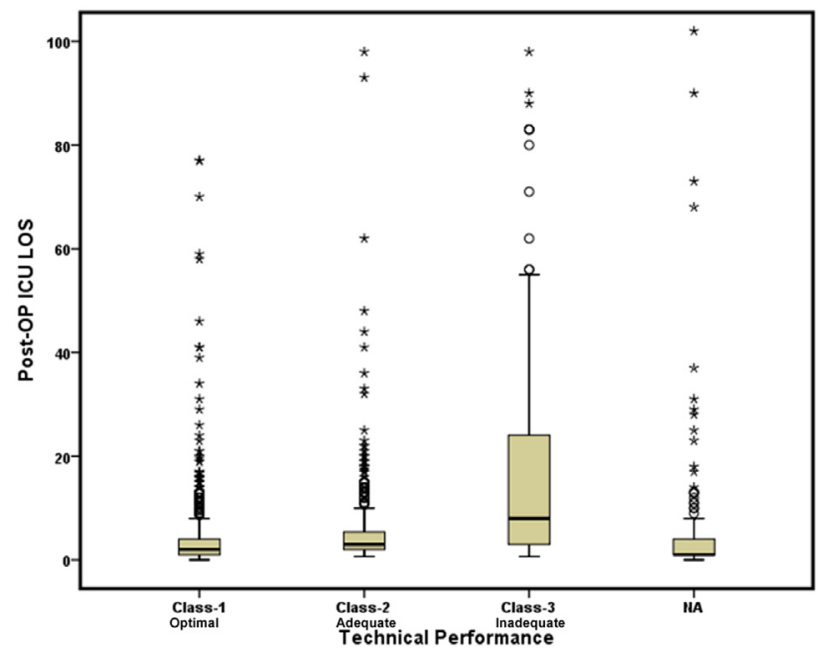

FIGURE E3. Mortality and adverse events across Risk Adjustment for Congenital Heart Surgery (RACHS-1) category according to the Technical Performance Score (TPS). The percentage of early mortality and adverse events in each TPS class using the RACHS-1 category. Class 3 (inadequate) TPS was significantly associated with greater rates of mortality and adverse events across RACHS- 1 categories 2 and more, with the higher RACHS- 1 categories having greater events rates. $N A \&<18$ years, Patients aged $<18$ years who could not be assigned a RACHS- 1 category. ICU, Intensive care unit; $L O S$, length of stay. 
TABLE E1. Unadjusted comparison of outcomes according to technical performance score $(n=1926)$

\begin{tabular}{lcccc}
\hline & & & TPS & \\
\cline { 2 - 5 } \multicolumn{1}{c}{ Variable } & $\begin{array}{c}\text { Class 1 } \\
\text { (optimal; } \mathbf{n}=\mathbf{9 5 6})\end{array}$ & $\begin{array}{c}\text { Class 2 } \\
\text { (adequate; } \mathbf{n}=\mathbf{5 8 4})\end{array}$ & $\begin{array}{c}\text { Class 3 (inadequate; } \\
\mathbf{n}=\mathbf{2 2 6} \text { ) }\end{array}$ & $\begin{array}{c}\text { NA (TPS not assigned; } \\
\mathbf{n}=\mathbf{1 6 0})\end{array}$ \\
\hline In-hospital mortality & $6 / 956(0.6)$ & $3 / 584(0.5)$ & $36 / 226(15.9)$ & $6 / 160(3.8)$ \\
Adverse events & $29 / 956(3.0)$ & $14 / 584(2.4)$ & $60 / 226(26.5)$ & $8 / 160(5.0)$ \\
Postoperative ICU LOS & $2(0-366)$ & $3(1-98)$ & $8(1-424)$ & $1(0-376)$ \\
\hline Categorical variables presented as n $(\%)$ and continuous variables as median (range). Class 3 (inadequate) TPS had a $P<.001$ for all outcomes. TPS, Technical Performance \\
Score; $N A$, not assigned; $I C U$, intensive care unit; $L O S$, length of stay.
\end{tabular}

TABLE E2. Univariate analysis of in-hospital mortality $(n=51 / 1926)$

\begin{tabular}{|c|c|c|c|c|c|c|c|c|c|}
\hline Variable & Total & $\begin{array}{c}\text { In-hospital } \\
\text { death (n) }\end{array}$ & $\begin{array}{c}\text { Mortality } \\
\text { rate }(\%)\end{array}$ & $\begin{array}{c}P \\
\text { value }\end{array}$ & Variable & Total & $\begin{array}{c}\text { adverse } \\
\text { events (n) }\end{array}$ & $\begin{array}{c}\text { event } \\
\text { rate }(\%)\end{array}$ & $\begin{array}{c}P \\
\text { value }\end{array}$ \\
\hline TPS & & & & $<.001 *$ & TPS & & & & $<.001^{*}$ \\
\hline Class 1, optimal & 956 & 6 & 0.6 & & Class 1, optimal & 956 & 29 & 3.0 & \\
\hline Class 2, adequate & 584 & 3 & 0.5 & & Class 2, adequate & 584 & 14 & 2.4 & \\
\hline Class 3 , inadequate & 226 & 36 & 15.9 & & Class 3 , inadequate & 226 & 60 & 26.5 & \\
\hline NA, no TPS could be assigned & 160 & 6 & 3.8 & & NA, no TPS could be & 160 & 8 & 5.0 & \\
\hline RACHS- 1 risk category & & & & $<.001 *$ & assigned & & & & \\
\hline 1 & 179 & 0 & 0.0 & & RACHS-1 risk category & & & & $<.001^{*}$ \\
\hline 2 & 526 & 3 & 0.6 & & 1 & 179 & 0 & 0.0 & \\
\hline 3 & 594 & 13 & 2.0 & & 2 & 526 & 10 & 1.9 & \\
\hline 4 & 186 & 14 & 7.5 & & 3 & 594 & 29 & 4.9 & \\
\hline 6 & 62 & 5 & 8.1 & & 4 & 186 & 31 & 16.7 & \\
\hline 7 (NA, age < 18 y) & 168 & 14 & 8.3 & & 6 & 62 & 14 & 22.6 & \\
\hline 8 (Adults) & 211 & 2 & 1.4 & & 7 (NA, age < 18 y) & 168 & 23 & 13.7 & \\
\hline Age at surgery & & & & $<.001^{*}$ & 8 (Adults) & 211 & 4 & 1.9 & \\
\hline$\leq 30 \mathrm{~d}$ & 322 & 25 & 7.8 & & Age at surgery & & & & $<.001 *$ \\
\hline $31 \mathrm{~d}$ to $1 \mathrm{y}$ & 520 & 17 & 3.3 & & $\leq 30 \mathrm{~d}$ & 322 & 48 & 14.9 & \\
\hline $1-18$ y & 873 & 6 & 0.7 & & $31 \mathrm{~d}$ to $1 \mathrm{y}$ & 520 & 36 & 6.9 & \\
\hline Prematurity & & & & $<.001 *$ & $1-18$ y & 873 & 23 & 2.6 & \\
\hline Yes & 67 & 13 & 19.4 & & Prematurity & & & & $<.001 *$ \\
\hline No & 1859 & 38 & 2.0 & & Yes & 67 & 16 & 23.9 & \\
\hline \multicolumn{4}{|c|}{ Extracardiac and/or genetic anomaly } & $.001^{*}$ & No & 1859 & 95 & 5.1 & \\
\hline Yes & 369 & 19 & 5.1 & & \multicolumn{2}{|c|}{ Extracardiac and/or genetic anomaly } & & & .354 \\
\hline No & 1557 & 32 & 2.1 & & Yes & 369 & 25 & 6.81 & \\
\hline \multirow{2}{*}{\multicolumn{5}{|c|}{$\begin{array}{l}\text { Patients age } \geq 18 \text { years constituted both RACHS- } 1 \text { risk category NA and adult } \\
\text { and age at surgery category } \geq 18 \text { years; these } 211 \text { patients were included } \\
\text { under RACHS- } 1 \text { risk category only (category } 8 \text { ). TPS, Technical Performance } \\
\text { Score; RACHS- }- \text {, Risk Adjustment in Congenital Heart Surgery; NA, not assigned. } \\
\text { *Statistically significant. }\end{array}$}} & No & 1557 & 86 & 5.5 & \\
\hline & & & & & $\begin{array}{l}\text { Patients aged } \geq 18 \text { years con } \\
\text { age at surgery category } \geq 18 \\
\text { risk category (category } 8 \text { ) or } \\
\text { Adjustment in Congenital } \mathrm{H}\end{array}$ & $\begin{array}{l}\text { both RA } \\
\text { hese } 211 \\
\text {, Techni } \\
\text { gery; } N A\end{array}$ & $\begin{array}{l}\text { CHS-1 risk cate } \\
\text { atients were inc } \\
\text { al Performance } \\
\text { not assigned. * }\end{array}$ & $\begin{array}{l}\text { gory NA and } \\
\text { luded under } \mathrm{I} \\
\text { Score; } R A C H \\
\text { tatistically si }\end{array}$ & $\begin{array}{l}\text { Adult and } \\
\text { ACHS-1 } \\
\text { S-1, Risk } \\
\text { gnificant. }\end{array}$ \\
\hline
\end{tabular}

396.e2 The Journal of Thoracic and Cardiovascular Surgery • January 2014 
TABLE E4. Univariate analysis for median postoperative ICU length of stay as surrogate for resource usage $(n=1926$ admissions $)$

\begin{tabular}{|c|c|c|c|}
\hline & \multicolumn{3}{|c|}{$\begin{array}{c}\text { Median } \\
\text { postoperative }\end{array}$} \\
\hline & Total (n) & ICU LOS & $P$ value \\
\hline \multicolumn{3}{|l|}{ TPS } & $<.001 *$ \\
\hline Class 1, optimal & 956 & $2(0-366)$ & \\
\hline Class 2, adequate & 584 & $3(1-98)$ & \\
\hline Class 3 , inadequate & 226 & $8(1-424)$ & \\
\hline NA, not able to assign TPS & 160 & $1(0-376)$ & \\
\hline \multicolumn{3}{|l|}{ RACHS-1 risk category } & $<.001^{*}$ \\
\hline 1 & 179 & $1(0-366)$ & \\
\hline 2 & 526 & $2(0-365)$ & \\
\hline 3 & 594 & $3(1-256)$ & \\
\hline 4 & 186 & $7(1-270)$ & \\
\hline 6 & 62 & $12(1-70)$ & \\
\hline 7 (NA and age < 18 y) & 168 & $5(1-424)$ & \\
\hline 8 (Adults) & 211 & $2(1-28)$ & \\
\hline \multicolumn{3}{|l|}{ Age at surgery } & $<.001^{*}$ \\
\hline$\leq 30 \mathrm{~d}$ & 322 & $7(1-376)$ & \\
\hline $31 \mathrm{~d}$ to $1 \mathrm{y}$ & 520 & $3(0-424)$ & \\
\hline $1-18$ y & 873 & $2(0-366)$ & \\
\hline \multicolumn{3}{|l|}{ Prematurity } & $<.001^{*}$ \\
\hline Yes & 67 & $8(1-376)$ & \\
\hline No & 1859 & $2(0-424)$ & \\
\hline \multicolumn{3}{|c|}{ Extracardiac and/or genetic anomaly } & $<.001^{*}$ \\
\hline Yes & 369 & $3(1-424)$ & \\
\hline No & 1557 & $2(0-424)$ & \\
\hline
\end{tabular}

